This item was submitted to Loughborough's Research Repository by the author.

Items in Figshare are protected by copyright, with all rights reserved, unless otherwise indicated.

\title{
Biaxial orientation of poly(vinyl chloride) compounds Part 2 -Structure- property relationships and their time dependency
}

PLEASE CITE THE PUBLISHED VERSION

\section{PUBLISHER}

(C) Maney Publishing

\section{VERSION}

VoR (Version of Record)

\section{LICENCE}

CC BY-NC-ND 4.0

\section{REPOSITORY RECORD}

Hitt, David J., and Marianne Gilbert. 2009. "Biaxial Orientation of Poly(vinyl Chloride) Compounds Part 2 structure-property Relationships and Their Time Dependency". figshare. https://hdl.handle.net/2134/4507. 
This item was submitted to Loughborough's Institutional Repository (https://dspace.lboro.ac.uk/) by the author and is made available under the following Creative Commons Licence conditions.

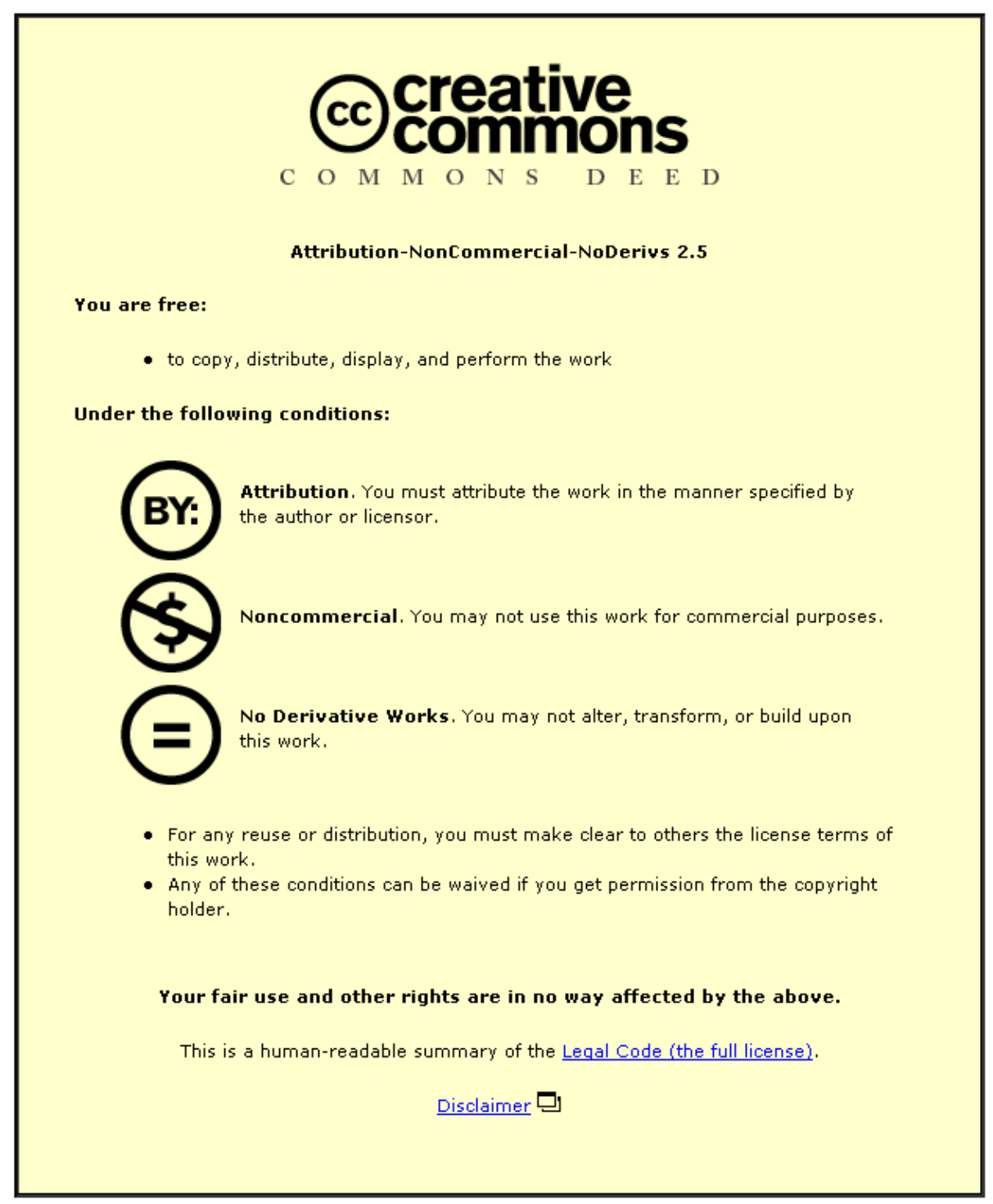

For the full text of this licence, please go to: http://creativecommons.org/licenses/by-nc-nd/2.5/ 


\title{
Biaxial orientation of poly(vinyl chloride) compounds Part 2 - Structure-property relationships and their time dependency
}

\author{
D. J. Hitt and M. Gilbert
}

X-ray diffraction and thermomechanical analysis have been used, respectively, to examine structural order and shrinkage behaviour for oriented samples of rigid and flexible poly(vinyl chloride) (PVC). Results were compared with previously measured tensile properties and structure-property relationships explored. X-ray diffraction showed that drawing produces planar crystallite orientation in PVC sheets. If drawing and subsequent annealing conditions are held constant, but draw ratio is varied, there is good correlation between structural order measured by X-ray diffraction and tensile strength. Increased annealing time and temperature improve crystallite order and dimensional stability, while tensile strength is unchanged. The greatest enhancement in tensile strength is achieved by stretching PVC towards its maximum draw ratio at $90^{\circ} \mathrm{C}$, but optimum thermal stability of the oriented structure is achieved when higher annealing temperatures are used. Room temperature recovery is observed for flexible PVC when the material has a glass transition temperature below ambient. This can be delayed by increased annealing time and temperature, and by increased draw ratio.

$\mathrm{PRC} / 1448$

(C) 2000 IoM Communications Ltd. The authors are in the Institute of Polymer Technology and Materials Engineering, Loughborough University, Loughborough, Leicestershire LE11 3TU, UK. Manuscript received 1 May 1998; accepted in final form 11 February 2000.

\section{INTRODUCTION}

In Part $1^{1}$ the mechanical properties were presented for three poly(vinyl chloride) (PVC) formulations, one rigid and two flexibles, that had been equally biaxially oriented under controlled conditions. The results were presented in two parts. First, the effects of drawing and annealing conditions on the tensile properties of oriented PVC were described. For all three formulations the greatest improvement in tensile strength occurred when they were drawn towards their maximum equal biaxial draw ratio at $90^{\circ} \mathrm{C}$. It had been shown in an earlier study ${ }^{2}$ that the maximum extensibility of all three PVC formulations occurred close to $90^{\circ} \mathrm{C}$. Second, a detailed study was reported on the effect of draw ratio on a wider range of mechanical properties. A PVC formulation containing $30 \mathrm{phr}$ of plasticiser was used. Both tensile and impact strength were found to increase with equal biaxial draw ratio. These were accompanied by reductions in the properties of elongation at break and tear strength. The observed changes in properties were explained in terms of chain alignment.
In addition to measuring tensile properties for the first part of Part 1, oriented samples of all three formulations were also characterised at that time using X-ray diffraction and thermomechanical analysis (TMA). The former technique was used to examine changes in the structure of PVC due to orientation while the latter technique was used to assess the permanence of the structure developed. As the principal aim of these studies has always been to understand structure-property relationships in oriented PVC, the data from the characterisation tests were compared with the reported tensile properties, ${ }^{1}$ and relationships were considered to explain any correlations. Further measurements on some of the oriented plasticised PVC samples enabled a clearer understanding of the properties of oriented PVC to be developed gradually. This arose because both plasticised PVC formulations in the study had a glass transition temperature $T_{\mathrm{g}}$ well below room temperature (see Table 1). Thus, oriented sheets of both formulations recovered slowly when stored at room temperature and the resultant changes in the properties of these materials over time

Table 1 PVC formulations

\begin{tabular}{|c|c|c|c|c|c|c|}
\hline \multirow[b]{2}{*}{ Formulation } & \multicolumn{5}{|c|}{ Components, phr } & \multirow[b]{2}{*}{$\begin{array}{l}\text { Maximum } \\
\text { equal biaxial } \\
\text { draw ratio }\end{array}$} \\
\hline & $\begin{array}{l}\text { PVC } \\
\text { Evipol } \\
\text { SH7020 }\end{array}$ & $\begin{array}{l}\text { Plasticiser } \\
\text { Di-iso-octyl } \\
\text { phthalate }\end{array}$ & $\begin{array}{l}\text { Stabiliser } \\
\text { Lankromark } \\
\text { LC68 (Ba-Cd) }\end{array}$ & $\begin{array}{l}\text { Lubricant } \\
\text { Stearic } \\
\text { acid }\end{array}$ & $T_{\mathrm{g}},{ }^{\circ} \mathrm{C}$ & \\
\hline 1 & 100 & $\ldots$ & 2 & 0.5 & 80 & $2 \cdot 0$ \\
\hline 2 & 100 & 30 & 2 & 0.5 & -3 & $2 \cdot 1$ \\
\hline 3 & 100 & 70 & 2 & 0.5 & -41 & $2 \cdot 4$ \\
\hline
\end{tabular}


has proved extremely valuable in relating structure to properties in oriented PVC.

In the present paper the X-ray diffraction and TMA data obtained from the oriented sheets at the time of Part 1 are presented, followed by similar data for the oriented plasticised PVC sheets that have been gathered over time. In the discussion of these results, initial proposals with regard to structure-property relationships are included so that the subsequent refinement of ideas due to the time dependent data can be seen.

\section{EXPERIMENTAL}

\section{Preparation of oriented PVC sheets}

Compression moulded sheets of the three formulations used in this study (Table 1) were prepared by the method described in Part 1. Biaxial stretching equipment $(\mathrm{BASE})^{3}$ was used to produce equally biaxially oriented samples under controlled conditions. The BASE has been designed as an attachment for an Instron tensile testing machine and has a stretching head located within a temperature controlled environmental cabinet. The movement of the crosshead of the Instron can be programmed precisely. This facility was used to drive the two perpendicular draw rods of the stretching head, one directly and the other via a hydraulic link, simultaneously at constant speeds. Samples are attached to the stretching head by means of four sets of ten grips which move apart proportionately as the head opens. After controlled stretching, samples were annealed under restraint in the environmental cabinet of the BASE and then cooled to ambient temperature before being released from the grips. All samples were marked with a precise grid of 100 squares of $10 \times 10 \mathrm{~mm}$ before stretching so that draw ratios of oriented sheets could be determined accurately at any time after stretching. The draw conditions of rate, ratio, and temperature and the subsequent annealing conditions of temperature and time were varied so that their effects on oriented PVC could be determined. The range of values for each of these variables is constrained by either the extensibility of PVC or by the specifications of the BASE. These limitations have been discussed in previous work. ${ }^{1,3}$

\section{Tensile properties}

The tensile properties reported in Part 1 are included in the present paper to enable comparisons to be made readily with the results of X-ray and TMA studies. Table 2 shows the tensile properties of undrawn samples of each formulation along with properties for oriented sheets produced under the conditions shown. (The consistency of the measured properties can be seen from the standard deviations given in the table.) As in the previous work, to simplify the presentation of results in this paper, the tensile properties of oriented sheets are expressed as property ratios, i.e. the values of stress at break $\sigma_{\mathrm{B}}$ and elongation at break $\varepsilon_{\mathrm{B}}$ for a drawn sheet are divided by the respective values of $\sigma_{\mathrm{B}}$ and $\varepsilon_{\mathrm{B}}$ for the corresponding undrawn material.

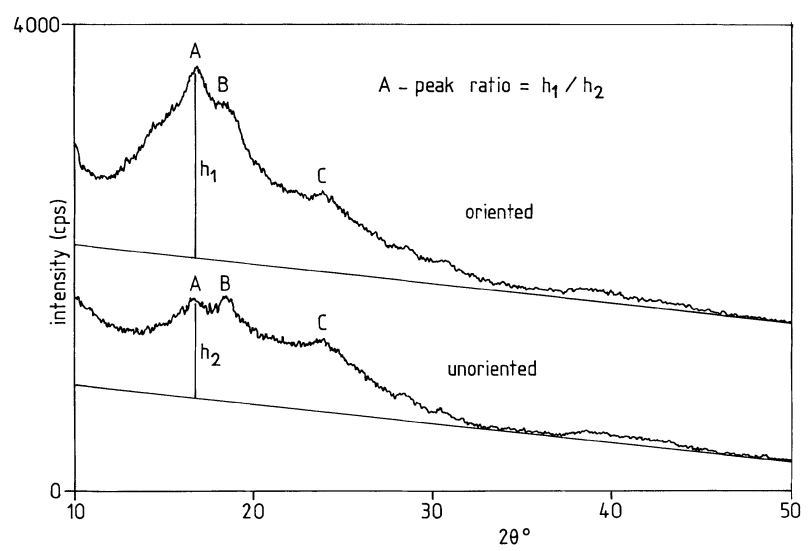

1 Typical X-ray diffraction patterns for unoriented and oriented PVC samples; pattern for oriented sample has been displaced on vertical axis

\section{Characterisation of oriented structures}

Descriptions are given below of how the techniques of X-ray diffraction and TMA have been applied in this study. Appropriate examples are used to illustrate the techniques.

\section{$X$-ray diffraction}

Commercial PVC is typically 55\% syndiotactic and both unplasticised and plasticised PVC are known to have about $5-10 \%$ crystallinity. ${ }^{4}$ Typical reflectance mode X-ray diffraction patterns are shown in Fig. 1 for oriented and unoriented samples. In both patterns there is a broad underlying peak due to scattering from the amorphous regions of the polymer. The peaks labelled A, B, and C are of primary interest as they arise from scattering by crystalline regions. ${ }^{4}$ The unit cell of PVC is known to be orthorhombic ${ }^{5}$ with the peak at $2 \theta \approx 16 \cdot 5^{\circ}(\mathrm{A})$ corresponding to the (200) reflection, that at $2 \theta \approx 18.5^{\circ}$ (B) to the (110) reflection, and that at $2 \theta \approx 24^{\circ}(\mathrm{C})$ to reflections from (201), (210), and (111) planes. Traces of this type are frequently used for measurements of crystallinity in PVC. ${ }^{4}$ For this purpose, a trace for an amorphous (quenched) sample is superimposed on that of the sample of interest, and crystallinity is calculated by measuring areas or intensities corresponding to crystalline peaks and comparing these with the area or intensity of the total diffraction pattern. A similar method has been used previously for the analysis of oriented PVC samples. ${ }^{6}$ However, in this work changes in individual peaks have been monitored. This can be more informative since crystallite alignment is of particular interest. Peaks $\mathrm{A}$ and $\mathrm{B}$ relate

Table 2 Tensile properties of undrawn and biaxially oriented PVC*

\begin{tabular}{|c|c|c|c|c|}
\hline \multirow{3}{*}{$\begin{array}{l}\text { Plasticiser, } \\
\text { phr }\end{array}$} & \multicolumn{4}{|c|}{ Tensile properties } \\
\hline & \multicolumn{2}{|l|}{$\sigma_{\mathrm{B}}, \mathrm{MPa}$} & \multicolumn{2}{|l|}{$\varepsilon_{\mathrm{B}}, \%$} \\
\hline & Undrawn & Drawn & Undrawn & Drawn \\
\hline 0 & $55.4(3.4)$ & $79.3(2.9)$ & $213(22)$ & $111(10)$ \\
\hline 30 & $29.8(1.4)$ & $51.9(2.9)$ & $331(22)$ & $271(6)$ \\
\hline 70 & $15.3(0.4)$ & $23 \cdot 2(1 \cdot 1)$ & $613(13)$ & 380 (19) \\
\hline
\end{tabular}

* Stretching conditions: draw $100 \mathrm{~mm} \mathrm{~min}^{-1}$ (given erroneously as $10 \mathrm{~mm} \mathrm{~min}^{-1}$ in Part 1 ) and $90^{\circ} \mathrm{C}$ to $1.5 \mathrm{X}$; anneal 10 min at $90^{\circ} \mathrm{C}$; standard deviations given in parentheses. 
to planes that are parallel to the chain axis. Peak $\mathrm{C}$ relates to several sets of planes and increases in intensity when the amount of three-dimensional crystallinity increases. ${ }^{7}$ However, changes in this peak cannot be related to specific crystal alignment.

$\mathrm{X}$-ray diffraction patterns were obtained using a JEOL DX-GE-2S generator fitted with a vertical goniometer of type DX-GO-S. The X-ray source was $\mathrm{Ni}$ filtered $\mathrm{Cu} K_{\alpha}$ radiation and was operated at $40 \mathrm{kV}$ and $30 \mathrm{~mA}$. Flat samples were placed on the goniometer stage and reflectance mode measurements of the X-ray intensity were obtained over the $2 \theta$ range of $10-50^{\circ}$.

Each time an X-ray diffraction pattern was obtained from an oriented sample a reference pattern was measured for an unstretched sample of the same formulation. When such corresponding pairs of patterns were compared, several consistent features became apparent that were applicable to all PVC formulations. These are illustrated by the pair of patterns shown in Fig. 1:

(i) at $2 \theta$ angles $>35^{\circ}$, very similar intensities are found in both patterns as only amorphous scattering occurs at these angles

(ii) orientation does not change the $\mathrm{C}$ peak significantly

(iii) the $\mathrm{A}$ and $\mathrm{B}$ peak intensities increase due to orientation with the change in the former being more dramatic

(iv) the B peak is generally slightly higher than the A peak for unoriented samples.

The significant changes in the A peak can be explained in terms of the structural changes occurring on drawing. They show that the number of (200) planes lying in the plane of the film has increased. This can be caused either by realignment of existing crystals in the plane of the film or by a stress induced increase in crystallinity. Recent structural studies have shown that both of these effects can occur. ${ }^{8}$ However, the two diffraction patterns presented in Fig. 1 show that the area of the $\mathrm{C}$ peak is almost unaffected by biaxial drawing, thereby indicating that the increase in crystallinity is quite small. The increase in the A peak corresponds to an increased alignment of the $b-c$ plane of the crystals in the plane of the film, which means that the $a$ axis is aligned normal to the plane of the film, as the unit cell of PVC is orthorhombic. The alignment of the (110) planes is also increased by biaxial drawing, but to a smaller extent. These planes are at an angle of $63^{\circ}$ to the (200) planes, so that they can be detected only when the $b$ axis tilts out of the plane of the film, while the $c$ axis remains in the plane of biaxial drawing.

Measurement of the A peak was used to assess the influence of biaxial orientation on structural order. The similarity between the patterns for an oriented sample and its corresponding unstretched material (at $2 \theta>35^{\circ}$ ) was employed to generate a reference baseline to measure the change in A peak intensity. For the unstretched material, a line was drawn connecting the X-ray intensity at $2 \theta=50^{\circ}$ to that at $2 \theta=35^{\circ}$ and extended to the low angle end of the pattern. A line of the same slope was then drawn below the pattern of the oriented sample starting from the intensity at $2 \theta=50^{\circ}$. These lines are shown
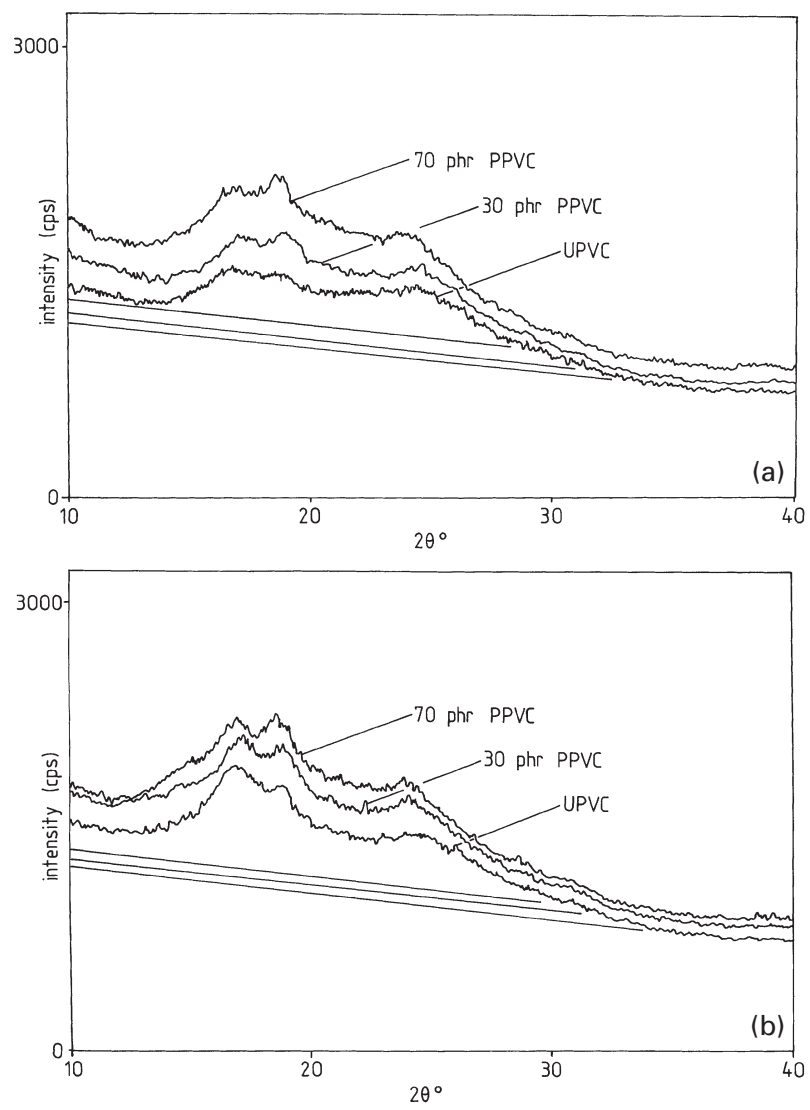

2 X-ray diffraction patterns for a unoriented and $b$ oriented samples of each formulation, drawn and annealed under conditions given in Table 2

for the patterns of Fig. 1. The change in A peak intensity is then expressed in terms of the 'A peak ratio'. This ratio provides a measure of structural order in the oriented sample relative to the unstretched state.

Figure $2 a$ and $b$ shows X-ray diffraction patterns for unstretched mouldings and oriented samples of each formulation. The oriented samples were produced under the conditions given in Table 2. The baselines generated from the patterns of Fig. $2 a$ have been added to Fig. $2 b$. The calculated A peak ratios were $1 \cdot 54,1 \cdot 44$, and $1 \cdot 17$, respectively for the formulations containing 0,30 , and $70 \mathrm{phr}$ of plasticiser. Thus, while X-ray intensity for both unstretched and oriented samples increases with increasing plasticiser content, the A peak ratio decreases. X-ray intensity is seen to increase with plasticiser content because the plasticiser swells the amorphous regions of the polymer.

\section{TMA}

It is well known that oriented polymer products shrink upon heating. To assess this behaviour, TMA can be used to measure changes in samples of oriented material as a function of temperature at a controlled heating rate. Two methods have been reported in the literature: measurement of retractive force ${ }^{9-11}$ and measurement of dimensional change. ${ }^{12-14}$ In the former, a sample is clamped so that its length is held constant during heating. A load cell is used to measure the retractive force exerted by the sample as it tries to shrink. In the second method a sample of known 

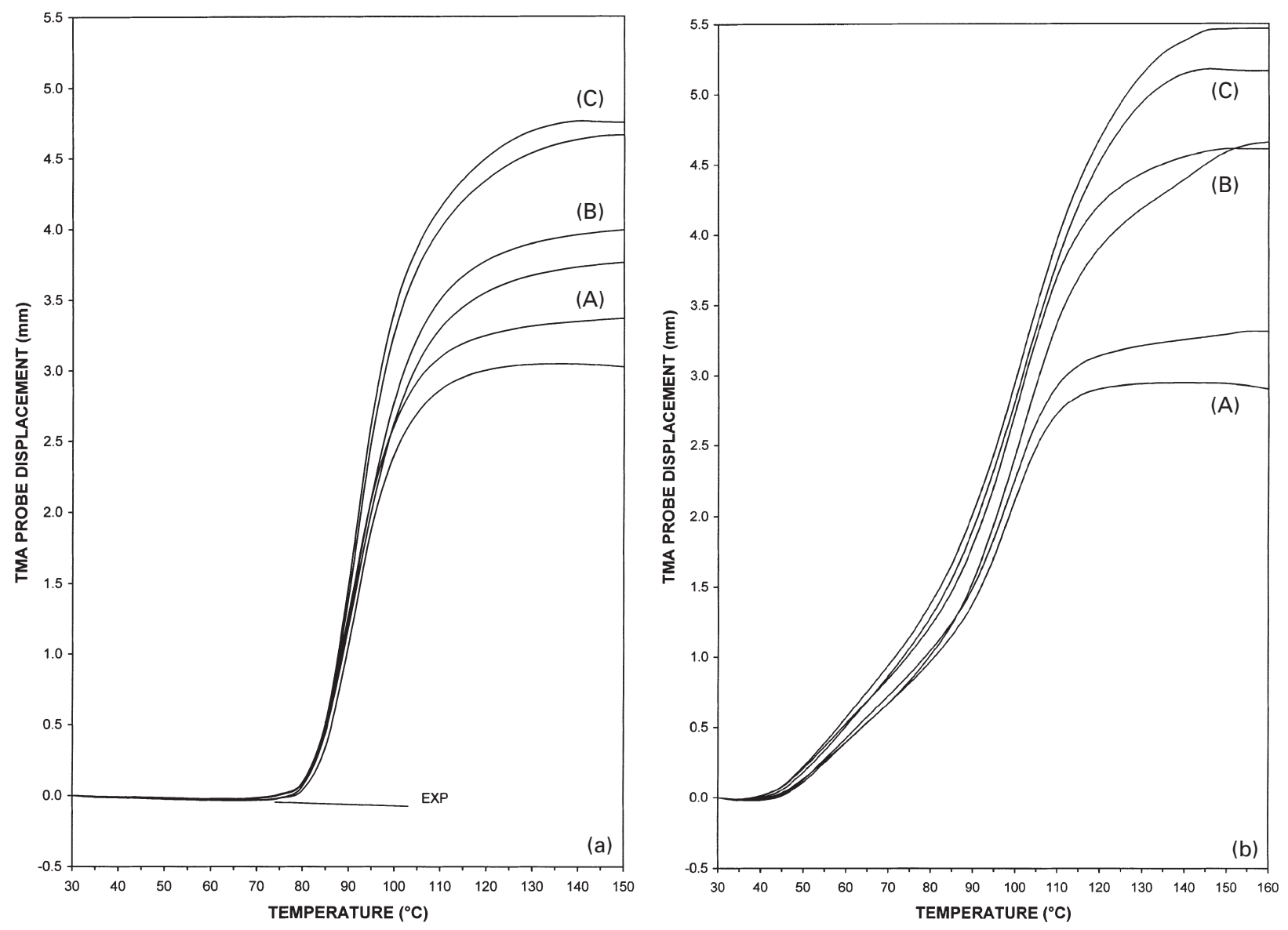

draw ratio: a $A$ 1.5; a $B$ 1.7; a $C 1.9 ; b$ A $1.5 ; b B 2.0 ; b C 2.4$

3 Pairs of TMA curves of dimensional change $v$. temperature for equally biaxially oriented samples of a rigid PVC and $b 70 \mathrm{phr}$ plasticised PVC stretched at $90^{\circ} \mathrm{C}$ to different draw ratios

length is held between a fixed grip and a free moving grip. A sensitive probe attached to the free moving grip is able to follow dimensional change in the sample during heating. The two methods have been applied to oriented rigid PVC. ${ }^{9,12}$ In both papers it was reported that changes in oriented samples occurred only as the $T_{\mathrm{g}}$ of the PVC formulation under test was approached.

In this work, a Mettler TMA40 Thermomechanical Analyser fitted with a film and fibre attachment was used to measure dimensional change in oriented samples. The attachment holds a narrow strip of material in its grips leaving a precise sample length of $10 \mathrm{~mm}$ exposed to heating. A controlled heating rate of $10 \mathrm{~K} \mathrm{~min}^{-1}$ was employed and a weight of $1 \mathrm{~g}$ was applied to the probe attached to the free moving grip.

As this study concerns equal biaxial stretching it was considered appropriate to test two samples from each oriented sheet: one cut parallel to the vertical draw direction of the $\mathrm{BASE}^{3}$ and one perpendicular to it. Figure $3 a$ and $b$ shows typical TMA curves of dimensional change against temperature for perpendicular pairs of samples of rigid PVC and of $70 \mathrm{phr}$ plasticised $\mathrm{PVC}$, respectively, stretched at $90^{\circ} \mathrm{C}$ to different draw ratios. A number of important points can be drawn from these figures. First, the expected behaviour that samples with higher draw ratios will shrink more ultimately can be clearly seen for both formulations. Second, as the rigid formulation has a $T_{\mathrm{g}}$ of $80^{\circ} \mathrm{C}$ (Table 1 ) TMA curves of this material initially show a steady slope due to expansion until $T_{\mathrm{g}}$ is approached, where the onset of shrinkage causes the curves to deviate from the expansion slope. For rigid PVC the shrinkage onset temperature can be taken as the temperature at which the shrinkage curve begins to deviate from the extended initial expansion slope (line labelled 'EXP' in Fig. 3a). Third, the $70 \mathrm{phr}$ plasticised formulation begins to shrink appreciably soon after heating has commenced, Fig. $3 b$, because its $T_{\mathrm{g}}$ is well below room temperature. As oriented products of such materials recover slowly when stored at room temperature their shrinkage onset temperatures are also below room temperature. In view of this it would be invalid to derive shrinkage onset temperatures from TMA curves obtained from the oriented plasticised samples of this study.

To enable a general comparison of the shrinkage behaviour in this study the pairs of TMA curves for each oriented sheet have been combined to generate a single 'area shrinkage' curve, using the following method based on Fig. 4. The two TMA samples define a post-stretch area of $100 \mathrm{~mm}^{2}$. If the equal biaxial draw ratio of the sheet is $\lambda$ then the original area in square millimetres defined by the two samples prior to stretching is $100 / \lambda^{2}$. Thus the maximum recoverable area through shrinkage is $100\left(1-1 / \lambda^{2}\right)$. If at a given temperature, the measured probe displacements for a 
DIRECTION OF VERTICAL

DRAW ROD OF BASE
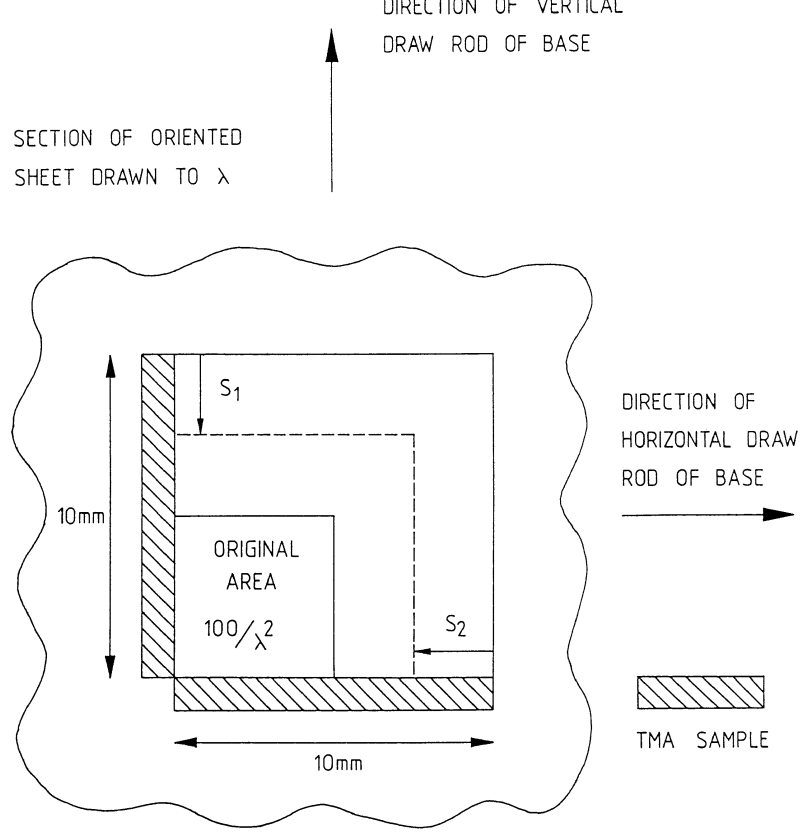

4 Basis for calculating area shrinkage for equally biaxially oriented sheet

pair of samples are $S_{1}(\mathrm{~mm})$ and $S_{2}(\mathrm{~mm})$, then it can be shown that the area shrinkage of the sample $A_{\mathrm{S}}$ as a percentage of the maximum recoverable area is

$$
A_{\mathrm{S}}(\%)=\left[10\left(S_{1}+S_{2}\right)-S_{1} S_{2}\right] /\left(1-1 / \lambda^{2}\right)
$$

This equation can be used to calculate $A_{\mathrm{S}}$ as a function of temperature. Presentation of TMA data in this way has a number of advantages. First, by definition an $A_{\mathrm{S}}$ of $100 \%$ means the oriented sample has returned to its original dimensions, and second, when draw ratio is the variable, shrinkage behaviour can be compared on the same scale. The latter is very well illustrated by Fig. $5 a$ and $b$ which shows, respectively, the calculated area shrinkage curves for the pairs of samples in Fig. $3 a$ and $b$.

\section{RESULTS}

Table 3 compares the properties of oriented sheets of each formulation produced under the same conditions. Tensile property ratios were calculated from the data in Table 2, X-ray A peak ratios were determined from Fig. 2. Figure 6 shows the area shrinkage curves for each formulation from which the shrinkage temperatures given in Table 3 were derived. The 5 and $50 \%$ shrinkage temperatures are convenient means of comparing shrinkage behaviour. The 5\% shrinkage temperature is a measure of when shrinkage

Table 3 Properties of undrawn and biaxially oriented PVC*

\begin{tabular}{|c|c|c|c|c|c|c|}
\hline \multirow{2}{*}{$\begin{array}{l}\text { Plasticiser } \\
\text { content, } \\
\text { phr }\end{array}$} & \multicolumn{2}{|c|}{$\begin{array}{l}\text { Tensile } \\
\text { property } \\
\text { ratios }\end{array}$} & \multirow{2}{*}{$\begin{array}{l}\text { X-ray } \\
\text { A peak } \\
\text { ratio }\end{array}$} & \multicolumn{3}{|c|}{$\begin{array}{l}\text { Shrinkage } \\
\text { temperatures, }{ }^{\circ} \mathrm{C}\end{array}$} \\
\hline & $\sigma_{\mathrm{B}}$ & $\varepsilon_{\mathrm{B}}$ & & Onset & $5 \% A_{s}$ & $50 \% A_{\mathrm{s}}$ \\
\hline 0 & 1.43 & 0.52 & 1.54 & $62 \cdot 0$ & 83.9 & $94 \cdot 1$ \\
\hline 30 & $1 \cdot 74$ & 0.82 & 1.44 & $\ldots$ & $54 \cdot 2$ & $84 \cdot 7$ \\
\hline 70 & 1.52 & 0.62 & $1 \cdot 17$ & $\ldots$ & $60 \cdot 2$ & $92 \cdot 8$ \\
\hline
\end{tabular}

* Stretching conditions as Table 2 . has become established and the difference between the 5 and $50 \%$ shrinkage temperatures is a good indicator of the slope of the curve once shrinkage has become established. Table 2 shows the expected results that equal biaxial orientation significantly enhances the tensile strength of both rigid and flexible PVC while reducing elongation at break. It appears that under the same stretching conditions, the A peak ratio is reduced by the addition of plasticiser. The influence of $T_{\mathrm{g}}$ on the shrinkage behaviour of rigid PVC is very apparent. While the shrinkage onset temperature is $62^{\circ} \mathrm{C}$ it is only when the $T_{\mathrm{g}}$ of the material, $80^{\circ} \mathrm{C}$, is exceeded that appreciable shrinkage occurs. The relatively poor dimensional stability of the 30 phr plasticised PVC formulation is well illustrated in Fig. 6.

Tables similar to Table 3 are presented to show the effects of the stretching variables: draw ratio, draw rate, draw temperature, annealing temperature, and annealing time. For each variable efforts were made, wherever practical, to maintain the same time interval between the preparation of the oriented sheets of a given formulation and any subsequent property measurements. In addition, because oriented sheets of plasticised PVC recover over time, the draw ratios given in the tables were those taken at the time the properties were measured and not those achieved immediately after stretching. The precise grid marked on each sheet enabled draw ratios to be determined accurately at any time.

\section{Effects due to stretching conditions}

\section{Draw ratio}

All three formulations have a maximum equal biaxial draw ratio at $90^{\circ} \mathrm{C}{ }^{1}$ These are given in Table 1 and refer to sheets immediately after removal from the BASE. The effect of drawing each formulation towards its maximum at $90^{\circ} \mathrm{C}$ can be seen in Table 4 . There is a significant improvement in tensile strength with increasing draw ratio, for example, the strength of the plasticised formulations is increased by around $65-70 \%$ at a draw ratio of $2 \cdot 0$. This increase in mechanical strength is matched by a similarly significant increase in X-ray A peak ratio. Draw ratio has little effect on the shrinkage onset temperature of the rigid formulation or upon the area shrinkage temperatures of each formulation. The latter is well illustrated by the area shrinkage curves of Fig. $5 a$ and $b$.

\section{Draw rate}

Table 5 compares the properties of pairs of samples of each formulation that were biaxially oriented at $1.3 \mathrm{~mm} \mathrm{~min}^{-1}$ and at $500 \mathrm{~mm} \mathrm{~min}^{-1}$, the respective minimum and maximum displacement rates of the stretching head of the BASE. The two rigid PVC samples have very similar properties, while the pairs of plasticised samples show some slight rate effects. Two of the three pairs of A peak ratios presented show a higher ratio at the lower rate and area shrinkage temperatures are improved at the higher rate. It appears that shrinkage onset temperature of the rigid formulation also improves slightly with rate.

\section{Draw and anneal temperatures}

As all three PVC formulations have their maximum extensibility at $90^{\circ} \mathrm{C}$, drawing at other temperatures 

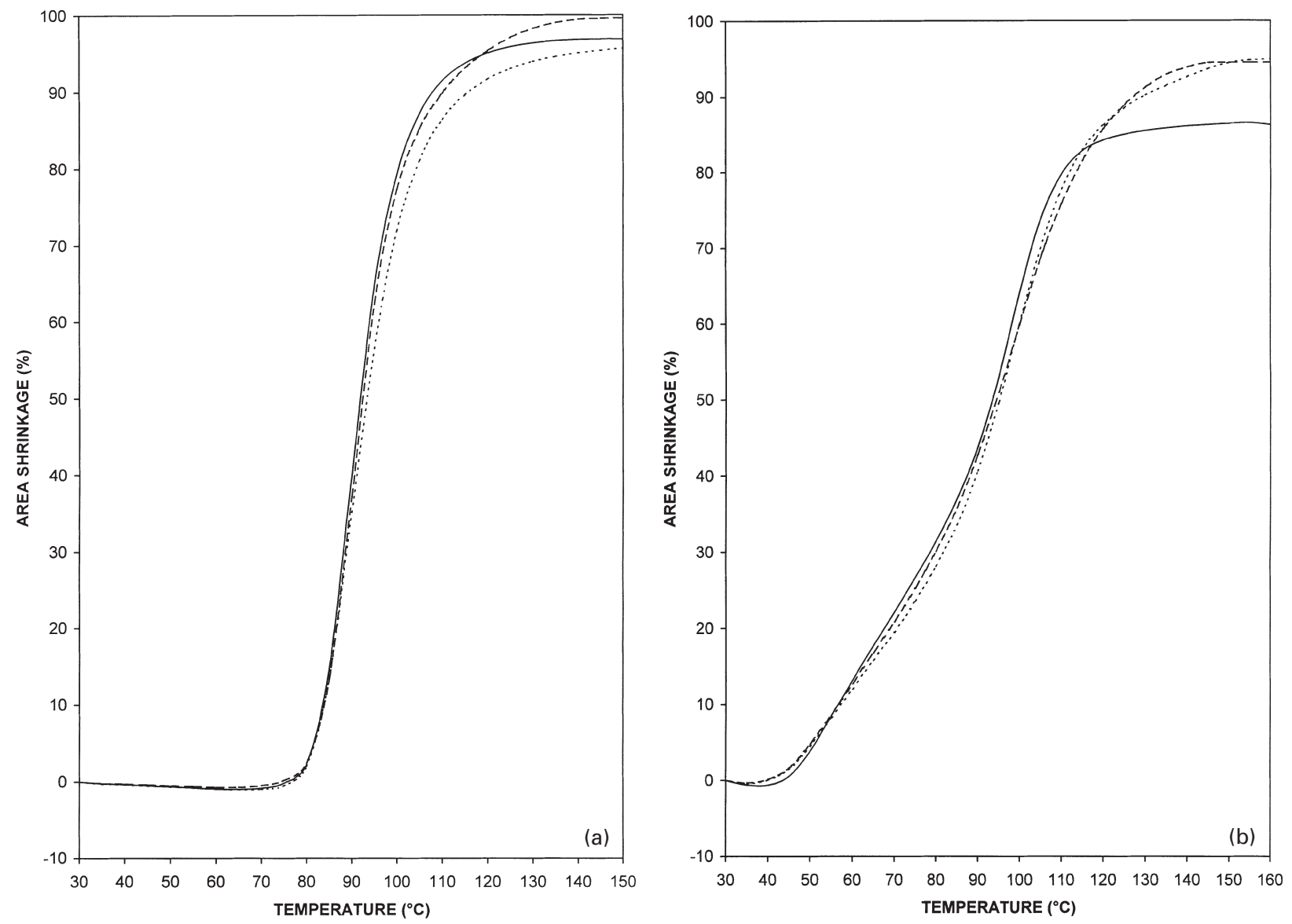

draw ratio: $a(-)$ 1.5, (--.--) 1.7, (--) 1.9; $b(-)$ 1.5, (-- - $)$ 2.0, (--) 2.4

5 Calculated area shrinkage curves for pairs of TMA curves shown in a Fig. $3 a$ and $b$ Fig. $3 b$

will naturally reduce the extent to which they can be biaxially oriented. (Note the BASE does not have the capacity to stretch the unplasticised PVC formulation at temperatures below its $T_{\mathrm{g}}$ of $80^{\circ} \mathrm{C}$.) Similarly, annealing at temperatures other than $90^{\circ} \mathrm{C}$ will also place a restriction on the draw ratio. For example, consider a PVC sample to be drawn at $90^{\circ} \mathrm{C}$ and subsequently annealed at $110^{\circ} \mathrm{C}$. If the sample is initially drawn to a ratio that exceeds the extensibility of the material at $110^{\circ} \mathrm{C}$ then the sample will fail on heating from 90 to $110^{\circ} \mathrm{C}$.

Draw ratios for each formulation had to be reduced to accommodate the various draw and anneal temperatures as given in Table 6. Reducing the draw temperature for plasticised formulations lessens the enhancement in tensile strength while improving the area shrinkage temperatures. Properties are also given for samples of each formulation drawn at $90^{\circ} \mathrm{C}$ and then annealed at temperatures of $90-110^{\circ} \mathrm{C}$. Increasing the annealing temperature has two effects. First, it delays the onset of shrinkage for the rigid PVC formulation and significantly improves the area shrinkage temperatures of all three formulations. Second, it increases the A peak ratio for two of three formulations, except for the $30 \mathrm{phr}$ plasticised formulation. By comparison annealing temperature has little effect on tensile properties.

\section{Annealing time}

Table 7 shows that increasing the annealing time for oriented samples of rigid PVC and $70 \mathrm{phr}$ plasticised
PVC has similar effects as increasing annealing temperature, i.e. the A peak ratio is increased and shrinkage is delayed. Similar effects due to increased annealing time can be seen in Table 5 for the $30 \mathrm{phr}$ plasticised formulation. Annealing time has little effect on tensile strength. It produces marginal changes to the strength of the rigid PVC and $30 \mathrm{phr}$ plasticised PVC formulations, while the strength values for the 70 phr plasticised PVC formulation suggest there may be an optimum annealing time for this material.

\section{Time dependent behaviour}

Initially, four oriented plasticised PVC samples were chosen in order to examine the effect of time on properties. The samples were originally biaxially drawn and annealed under the conditions given in Table 8 . The draw ratios in the table show that on release from the grips of the BASE the samples immediately show significant elastic recovery, especially the $70 \mathrm{phr}$ plasticised formulation. The subsequent loss in draw ratio over time is slower.

Tensile properties of the sheets were measured 100 and 800 days after stretching. Table 9 shows that over this period the tensile strength of all three sheets had decreased slightly while elongation at break had increased.

A sample of each oriented sheet was examined by X-ray diffraction on a number of occasions and A peak ratios derived. These values are plotted against time in Fig. 7. This shows the ratio decreases continu- 


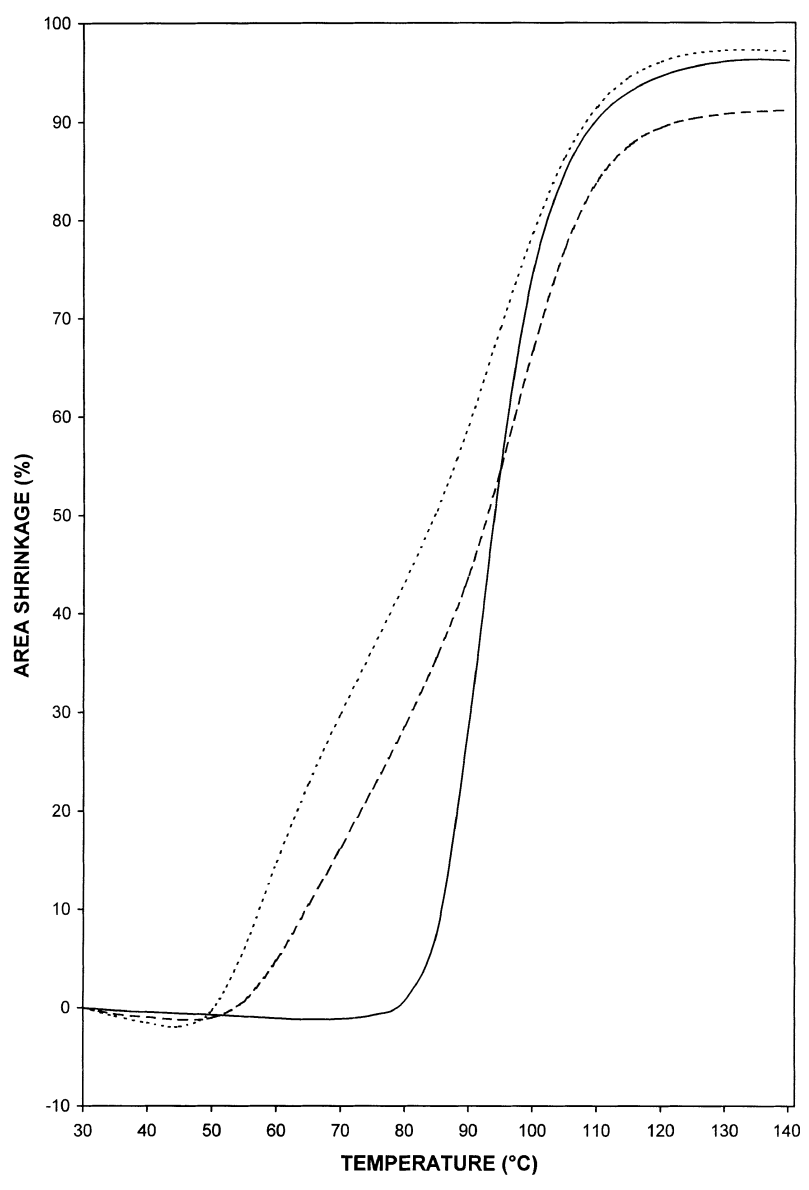

(---) 30 phr pPVC; (--) 70 phr pPVC; (-) uPVC

6 Area shrinkage curves for oriented samples of plasticised (p) and unplasticised (u) PVC drawn and annealed under conditions given in Table 2

ously over time for oriented samples of the $70 \mathrm{phr}$ plasticised PVC formulation, while for samples of the $30 \mathrm{phr}$ plasticised PVC formulation it decreases initially before settling to a relatively constant value.

Samples of each sheet were also examined by TMA at regular intervals. Area shrinkage temperatures were determined, on the basis of the sample draw ratio at the time of measurement, and found to increase over time for all four oriented sheets (Fig. 8).

To complement the above results a further set of oriented sheets were prepared under the stretching

Table 4 Effect of draw ratio on properties of biaxially oriented PVC*

\begin{tabular}{|c|c|c|c|c|c|c|c|}
\hline \multirow{2}{*}{$\begin{array}{l}\text { Plasticiser } \\
\text { content, } \\
\text { phr }\end{array}$} & \multirow{2}{*}{$\begin{array}{l}\text { Draw } \\
\text { ratio }\end{array}$} & \multicolumn{2}{|c|}{$\begin{array}{l}\text { Tensile } \\
\text { property } \\
\text { ratios }\end{array}$} & \multirow{2}{*}{$\begin{array}{l}\text { X-ray } \\
\text { A peak } \\
\text { ratio }\end{array}$} & \multicolumn{3}{|c|}{$\begin{array}{l}\text { Shrinkage } \\
\text { temperatures, }{ }^{\circ} \mathrm{C}\end{array}$} \\
\hline & & $\sigma_{\mathrm{B}}$ & $\varepsilon_{\mathrm{B}}$ & & Onset & $5 \% A_{s}$ & $50 \% A_{\mathrm{s}}$ \\
\hline 0 & 1.5 & $1 \cdot 74$ & 0.55 & 1.54 & 60.5 & $82 \cdot 6$ & $92 \cdot 0$ \\
\hline 0 & $1 \cdot 7$ & $1 \cdot 85$ & 0.40 & 1.87 & $61 \cdot 0$ & $82 \cdot 1$ & 93.5 \\
\hline 0 & 1.9 & 1.99 & 0.44 & $2 \cdot 11$ & $59 \cdot 0$ & $82 \cdot 1$ & $92 \cdot 6$ \\
\hline 30 & 1.5 & $1 \cdot 32$ & 0.85 & $1 \cdot 33$ & $\ldots$ & $45 \cdot 3$ & 83.9 \\
\hline 30 & $2 \cdot 0$ & $1 \cdot 64$ & 0.56 & 1.75 & $\ldots$ & $43 \cdot 4$ & $85 \cdot 1$ \\
\hline 70 & 1.5 & $1 \cdot 36$ & 0.69 & $1 \cdot 18$ & $\ldots$ & $50 \cdot 8$ & 93.4 \\
\hline 70 & $2 \cdot 0$ & $1 \cdot 70$ & 0.41 & $1 \cdot 39$ & $\ldots$ & $50 \cdot 1$ & $95 \cdot 1$ \\
\hline 70 & $2 \cdot 4$ & $2 \cdot 12$ & 0.36 & 1.90 & $\ldots$ & $50 \cdot 3$ & $94 \cdot 4$ \\
\hline
\end{tabular}

* Stretching conditions: draw $10 \mathrm{~mm} \mathrm{~min}^{-1}$ and $90^{\circ} \mathrm{C}$; anneal $10 \mathrm{~min}$ at $90^{\circ} \mathrm{C}$ (unplasticised PVC) and $30 \mathrm{~min}$ at $90^{\circ} \mathrm{C}$ (plasticised PVC).

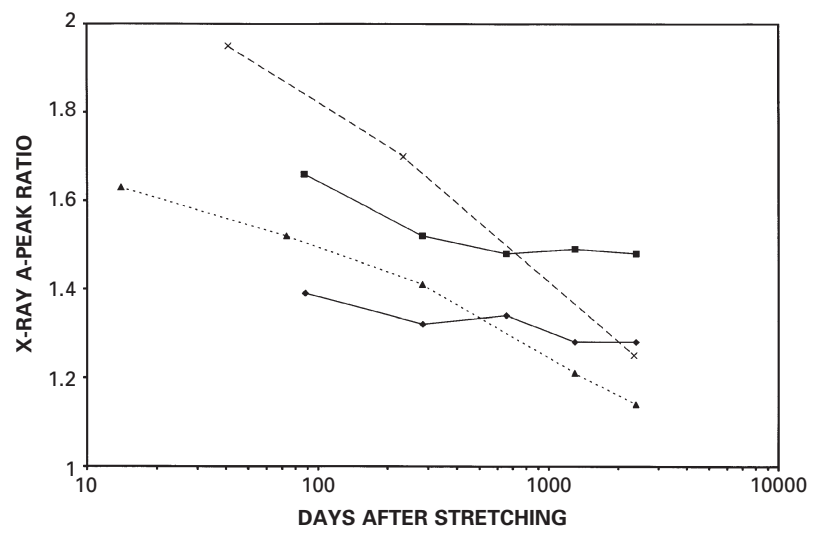

(४) $30 \mathrm{phr}$ pPVC, sample T31; (匹) $30 \mathrm{phr}$ pPVC, sample T32; (4) 70 phr pPVC, sample T71; (x) 70 phr pPVC, sample T72

7 Change in X-ray A peak ratio with time for oriented plasticised PVC (samples of Table 8)

conditions given in Table 10. A PVC formulation containing $30 \mathrm{phr}$ of the plasticiser diisodecyl phthalate (DIDP) was used. Unoriented sheets of this material had a tensile strength of $30.2 \mathrm{MPa}$ and an elongation at break of $316 \%$. Its maximum equal biaxial draw ratio at $90^{\circ} \mathrm{C}$ was $2 \cdot 2$.

The overall dimensions of the grid marked on each sheet were measured at regular intervals starting $2.5 \mathrm{~h}$ after removal from the BASE. The loss in area of each sheet with time is shown in Fig. $9 a$. Room temperature recovery is slowed by increasing annealing temperature (compare sheets drawn to 1.49), increasing annealing time (compare sheets drawn to 1.84) and apparently decreasing draw ratio (compare sheets annealed at $90^{\circ} \mathrm{C}$ for $10 \mathrm{~min}$ ). However, a different perspective arises from Fig. $9 b$, in which the changes in area are expressed as a percentage of the appropriate maximum recoverable area (i.e. the area of the sheet $2.5 \mathrm{~h}$ after removal from the BASE minus the area of the sheet before stretching). While the annealing effects remain as before, increasing the draw ratio is now seen to reduce room temperature recovery. As Fig. $9 b$ relates recovery to the amount of biaxial orientation imposed on each of the stretched sheets, this figure is considered to be a more appropriate way of interpreting room temperature recovery than Fig. $9 a$. Table 10 confirms a number of previous observations. Increasing the draw ratio improves tensile strength substantially while having no discernible effect on shrinkage temperature (sheets 1,5 , and 6 ). Increasing the annealing temperature has little effect on tensile strength but improves elongation at break and delays shrinkage (sheets 1,2, and 3). Over time there is generally a slight improvement in both tensile strength and elongation at break. The increase in the former is contrary to the general reduction in strength seen in Table 9. Area shrinkage temperatures increase over time confirming the results of Fig. 8.

\section{DISCUSSION}

\section{Structure-property relationships}

It is generally accepted that PVC, whether unplasticised or plasticised, has a three-dimensional network structure in which small crystallites act as physical 
crosslinks. ${ }^{4}$ When plasticiser is added to PVC it enters the amorphous regions of the network while leaving the crystallites largely unaffected. Many of the changes in the properties of PVC due to drawing and annealing can be interpreted in terms of this network structure.
The intensity of the A peak in reflectance mode $\mathrm{X}$-ray diffraction patterns of $\mathrm{PVC}$ is related to the number of (200) planes of the PVC unit cell, lying in the plane of the PVC sheet. The significant increase in A peak ratio with biaxial draw ratio (Table 4) shows that drawing aligns crystallites in the plane of

Table 5 Effect of draw rate on properties of biaxially oriented PVC*

\begin{tabular}{|c|c|c|c|c|c|c|c|c|c|}
\hline \multirow{2}{*}{$\begin{array}{l}\text { Plasticiser } \\
\text { content, } \\
\text { phr }\end{array}$} & \multirow{2}{*}{$\begin{array}{l}\text { Draw rate, } \\
\mathrm{mm} \min ^{-1}\end{array}$} & \multirow{2}{*}{$\begin{array}{l}\text { Draw } \\
\text { ratio }\end{array}$} & \multirow{2}{*}{$\begin{array}{l}\text { Anneal } \\
\text { time, } \\
\text { min }\end{array}$} & \multicolumn{2}{|c|}{$\begin{array}{l}\text { Tensile property } \\
\text { ratios }\end{array}$} & \multirow{2}{*}{$\begin{array}{l}\text { X-ray } \\
\text { A peak } \\
\text { ratio }\end{array}$} & \multicolumn{3}{|c|}{$\begin{array}{l}\text { Shrinkage temperatures, } \\
{ }^{\circ} \mathrm{C}\end{array}$} \\
\hline & & & & $\sigma_{\mathrm{b}}$ & $\varepsilon_{\mathrm{b}}$ & & Onset & $5 \% A_{\mathrm{s}}$ & $50 \% A_{\mathrm{s}}$ \\
\hline 0 & $1 \cdot 3$ & $1 \cdot 8$ & 2 & $1 \cdot 70$ & 0.36 & 1.95 & $61 \cdot 5$ & $82 \cdot 8$ & $91 \cdot 7$ \\
\hline 0 & $500 \cdot 0$ & $1 \cdot 8$ & 2 & $1 \cdot 65$ & 0.36 & 1.94 & 63.0 & $82 \cdot 7$ & $90 \cdot 8$ \\
\hline 30 & $1 \cdot 3$ & $2 \cdot 0$ & 5 & $1 \cdot 64$ & 0.43 & 1.65 & $\ldots$ & $51 \cdot 4$ & $83 \cdot 8$ \\
\hline 30 & $500 \cdot 0$ & $2 \cdot 0$ & 5 & 1.69 & 0.42 & 1.69 & $\ldots$ & $52 \cdot 2$ & $85 \cdot 1$ \\
\hline 30 & $1 \cdot 3$ & 1.9 & 90 & $1 \cdot 74$ & 0.47 & 1.91 & $\ldots$ & 59.9 & $92 \cdot 1$ \\
\hline 30 & $500 \cdot 0$ & 1.9 & 90 & $1 \cdot 73$ & 0.45 & $1 \cdot 77$ & $\ldots$ & $62 \cdot 3$ & $98 \cdot 7$ \\
\hline 70 & $1 \cdot 3$ & 1.9 & 10 & $1 \cdot 49$ & 0.47 & $1 \cdot 87$ & $\ldots$ & $\ldots$ & $\ldots$ \\
\hline 70 & $500 \cdot 0$ & 1.9 & 10 & $1 \cdot 68$ & 0.45 & 1.69 & $\ldots$ & $\ldots$ & $\ldots$ \\
\hline 70 & $1 \cdot 3$ & 1.8 & 60 & $1 \cdot 60$ & 0.42 & $\ldots$ & $\ldots$ & 65.9 & $101 \cdot 8$ \\
\hline 70 & $500 \cdot 0$ & $1 \cdot 8$ & 60 & $1 \cdot 46$ & 0.40 & $\ldots$ & $\ldots$ & 68.0 & $104 \cdot 6$ \\
\hline
\end{tabular}

* Conditions: draw temperature $90^{\circ} \mathrm{C}$; anneal temperature $90^{\circ} \mathrm{C}$.

Table 6 Effect of draw and anneal temperatures on properties of biaxially oriented PVC*

\begin{tabular}{|c|c|c|c|c|c|c|c|c|c|}
\hline \multirow{2}{*}{$\begin{array}{l}\text { Plasticiser } \\
\text { content, } \\
\text { phr }\end{array}$} & \multirow{2}{*}{$\begin{array}{l}\text { Draw } \\
\text { temp., } \\
{ }^{\circ} \mathrm{C}\end{array}$} & \multirow{2}{*}{$\begin{array}{l}\text { Draw } \\
\text { ratio }\end{array}$} & \multirow{2}{*}{$\begin{array}{l}\text { Anneal } \\
\text { temp., } \\
{ }^{\circ} \mathrm{C}\end{array}$} & \multicolumn{2}{|c|}{$\begin{array}{l}\text { Tensile property } \\
\text { ratios }\end{array}$} & \multirow{2}{*}{$\begin{array}{l}\text { X-ray } \\
\text { A peak } \\
\text { ratio }\end{array}$} & \multicolumn{3}{|c|}{$\begin{array}{l}\text { Shrinkage temperatures, } \\
{ }^{\circ} \mathrm{C}\end{array}$} \\
\hline & & & & $\sigma_{\mathrm{b}}$ & $\varepsilon_{\mathrm{b}}$ & & Onset & $5 \% A_{\mathrm{s}}$ & $50 \% A_{s}$ \\
\hline 30 & 60 & 1.5 & 90 & $1 \cdot 68$ & 0.75 & $1 \cdot 37$ & $\ldots$ & $57 \cdot 2$ & $96 \cdot 1$ \\
\hline 30 & 90 & 1.5 & 90 & $1 \cdot 74$ & 0.82 & $1 \cdot 44$ & $\ldots$ & $54 \cdot 2$ & $84 \cdot 7$ \\
\hline 70 & 23 & $1 \cdot 7$ & 90 & $1 \cdot 37$ & 0.55 & $1 \cdot 42$ & $\ldots$ & $64 \cdot 3$ & $100 \cdot 0$ \\
\hline 70 & 90 & $1 \cdot 7$ & 90 & $1 \cdot 67$ & 0.62 & $1 \cdot 32$ & $\ldots$ & $61 \cdot 3$ & $96 \cdot 3$ \\
\hline 0 & 90 & 1.5 & 90 & $1 \cdot 43$ & 0.52 & 1.54 & $62 \cdot 0$ & 83.9 & $94 \cdot 1$ \\
\hline 0 & 90 & 1.5 & 110 & $1 \cdot 40$ & 0.52 & 1.67 & 66.0 & $85 \cdot 8$ & 114.6 \\
\hline 30 & 90 & 1.5 & 90 & $1 \cdot 74$ & 0.82 & $1 \cdot 44$ & $\ldots$ & $54 \cdot 2$ & $84 \cdot 7$ \\
\hline 30 & 90 & 1.5 & 100 & $1 \cdot 81$ & 0.72 & $1 \cdot 41$ & $\ldots$ & $59 \cdot 0$ & $103 \cdot 3$ \\
\hline 30 & 90 & 1.5 & 110 & $1 \cdot 77$ & 0.84 & $1 \cdot 48$ & $\ldots$ & $61 \cdot 0$ & $116 \cdot 2$ \\
\hline 70 & 90 & $1 \cdot 7$ & 90 & $1 \cdot 67$ & 0.62 & $1 \cdot 32$ & $\ldots$ & $61 \cdot 3$ & $96 \cdot 3$ \\
\hline 70 & 90 & $1 \cdot 7$ & 110 & $1 \cdot 52$ & 0.63 & $1 \cdot 46$ & $\ldots$ & $67 \cdot 5$ & $122 \cdot 7$ \\
\hline
\end{tabular}

*Conditions: draw rate $100 \mathrm{~mm} \mathrm{~min}^{-1}$; anneal time $10 \mathrm{~min}$.

Table 7 Effect of annealing time on properties of biaxially oriented unplasticised PVC and 70 phr plasticised PVC*

\begin{tabular}{|c|c|c|c|c|c|c|c|c|}
\hline \multirow{2}{*}{$\begin{array}{l}\text { Plasticiser } \\
\text { content, } \\
\text { phr }\end{array}$} & \multirow{2}{*}{$\begin{array}{l}\text { Draw } \\
\text { ratio }\end{array}$} & \multirow{2}{*}{$\begin{array}{l}\text { Anneal } \\
\text { time at } \\
90^{\circ} \mathrm{C} \text {, } \\
\text { min }\end{array}$} & \multicolumn{2}{|c|}{$\begin{array}{l}\text { Tensile property } \\
\text { ratios }\end{array}$} & \multirow{2}{*}{$\begin{array}{l}\text { X-ray } \\
\text { A peak } \\
\text { ratio }\end{array}$} & \multicolumn{3}{|c|}{$\begin{array}{l}\text { Shrinkage temperatures, } \\
{ }^{\circ} \mathrm{C}\end{array}$} \\
\hline & & & $\sigma_{\mathrm{b}}$ & $\varepsilon_{\mathrm{b}}$ & & Onset & $5 \% A_{\mathrm{s}}$ & $50 \% A_{\mathrm{s}}$ \\
\hline 0 & $1 \cdot 85$ & 2 & 1.65 & 0.38 & $\ldots$ & 63.0 & $82 \cdot 7$ & $90 \cdot 8$ \\
\hline 0 & $1 \cdot 85$ & 5 & $1 \cdot 60$ & 0.36 & $\ldots$ & $64 \cdot 0$ & $84 \cdot 2$ & $94 \cdot 4$ \\
\hline 70 & $2 \cdot 0$ & 5 & $1 \cdot 74$ & 0.41 & $1 \cdot 61$ & $\ldots$ & $53 \cdot 4$ & 89.6 \\
\hline 70 & $2 \cdot 0$ & 20 & $1 \cdot 87$ & 0.45 & $1 \cdot 73$ & $\ldots$ & 53.8 & $91 \cdot 6$ \\
\hline 70 & $2 \cdot 0$ & 60 & $1 \cdot 78$ & 0.42 & $1 \cdot 85$ & $\ldots$ & $54 \cdot 8$ & $95 \cdot 4$ \\
\hline
\end{tabular}

* Draw conditions: unplasticised PVC $500 \mathrm{~mm} \mathrm{~min}^{-1}$ at $90^{\circ} \mathrm{C}$; plasticised PVC $10 \mathrm{~mm} \mathrm{~min}^{-1}$ at $90^{\circ} \mathrm{C}$.

Table 8 Biaxial stretching conditions and draw ratios for plasticised PVC samples examined over time

\begin{tabular}{|c|c|c|c|c|c|c|c|c|c|}
\hline \multirow[b]{3}{*}{ Sample } & \multirow{3}{*}{$\begin{array}{l}\text { Plasticiser, } \\
\text { phr }\end{array}$} & \multirow{3}{*}{$\begin{array}{l}\text { Draw } \\
\text { rate, } \\
\mathrm{mm} \mathrm{min}^{-1}\end{array}$} & \multirow{3}{*}{$\begin{array}{l}\text { Draw } \\
\text { temp., } \\
{ }^{\circ} \mathrm{C}\end{array}$} & \multirow{3}{*}{$\begin{array}{l}\text { Anneal } \\
\text { temp., } \\
{ }^{\circ} \mathrm{C}\end{array}$} & \multirow{3}{*}{$\begin{array}{l}\text { Anneal } \\
\text { time, } \\
\text { min }\end{array}$} & \multicolumn{4}{|l|}{ Sample draw ratios } \\
\hline & & & & & & \multirow{2}{*}{$\begin{array}{l}\text { Still gripped in } \\
\text { BASE after stretch }\end{array}$} & \multicolumn{3}{|c|}{ After removal from BASE } \\
\hline & & & & & & & Immediate & 9 days & 800 days \\
\hline T31 & 30 & 10 & 90 & 90 & 5 & $1 \cdot 52$ & $1 \cdot 50$ & $1 \cdot 45$ & $1 \cdot 38$ \\
\hline T32 & 30 & 10 & 90 & 90 & 5 & $2 \cdot 05$ & $2 \cdot 02$ & 1.97 & $1 \cdot 85$ \\
\hline T71 & 70 & 100 & 90 & 90 & 20 & $2 \cdot 18$ & 1.90 & $1 \cdot 86$ & $1 \cdot 79$ \\
\hline T72 & 70 & 100 & 90 & 90 & 20 & $2 \cdot 58$ & $2 \cdot 38$ & $2 \cdot 19$ & $2 \cdot 11$ \\
\hline
\end{tabular}




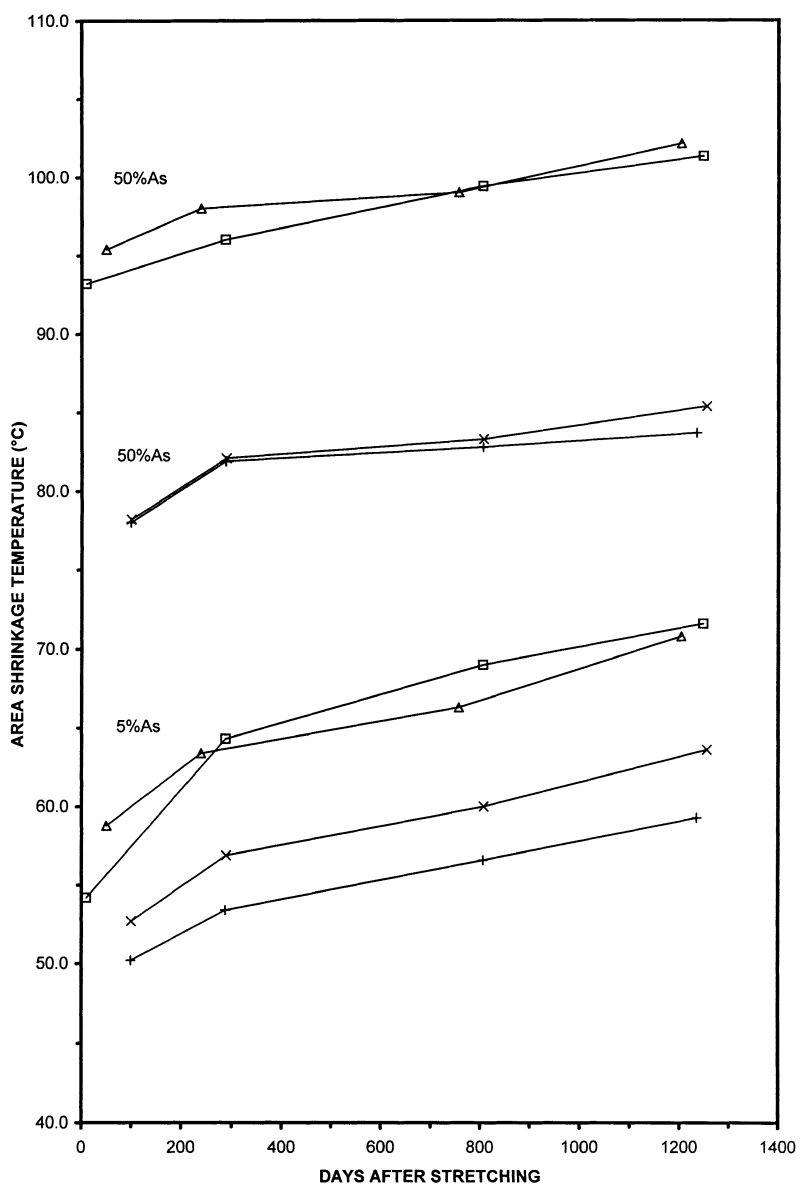

(x) 30 phr pPVC, T31; (+) 30 phr pPVC, T32; ( $\square) 70$ phr pPVC, T71; $(\triangle) 70$ phr pPVC, T72

8 Change in area shrinkage temperatures with time for oriented plasticised PVC (samples given in Table 8)

oriented PVC sheets. Gilbert et al. ${ }^{8}$ recently reported this effect for both uniaxially and equally biaxially oriented sheets of a commercially produced rigid PVC formulation. They also found that drawing had no significant effect on the intensity of the $\mathrm{B}$ peak and caused a small decrease in the intensity of the $C$ peak in X-ray diffraction patterns of PVC. This supports the use of the A peak as an indicator of crystallite orientation.

Results have also shown that the A peak intensity for oriented PVC sheets can be further increased by longer annealing times and higher annealing temperatures. As annealing cannot bring further crystallites into the plane of the oriented sheet it must perfect or add structure to existing crystallites to produce the observed effect. Vyvoda et al. ${ }^{15}$ had previously found that the maximum two-dimensional order in uniaxially oriented PVC occurred on annealing at $110^{\circ} \mathrm{C}$.

The dimensional stability of oriented structures has been assessed by TMA. Oriented sheets of the unplasticised PVC formulation begin to shrink at temperatures below the $T_{\mathrm{g}}$ of the material. DeVries and Bonnebat $^{9}$ also found this in their work on the thermoformability of chlorinated PVC. An oriented sheet of an unmodified PVC, $T_{\mathrm{g}} 74^{\circ} \mathrm{C}$, was shown to begin to shrink at $\sim 64^{\circ} \mathrm{C}$ while an oriented sheet of a chlorinated PVC began to shrink at a temperature approaching its $T_{\mathrm{g}}$ of $101^{\circ} \mathrm{C}$.
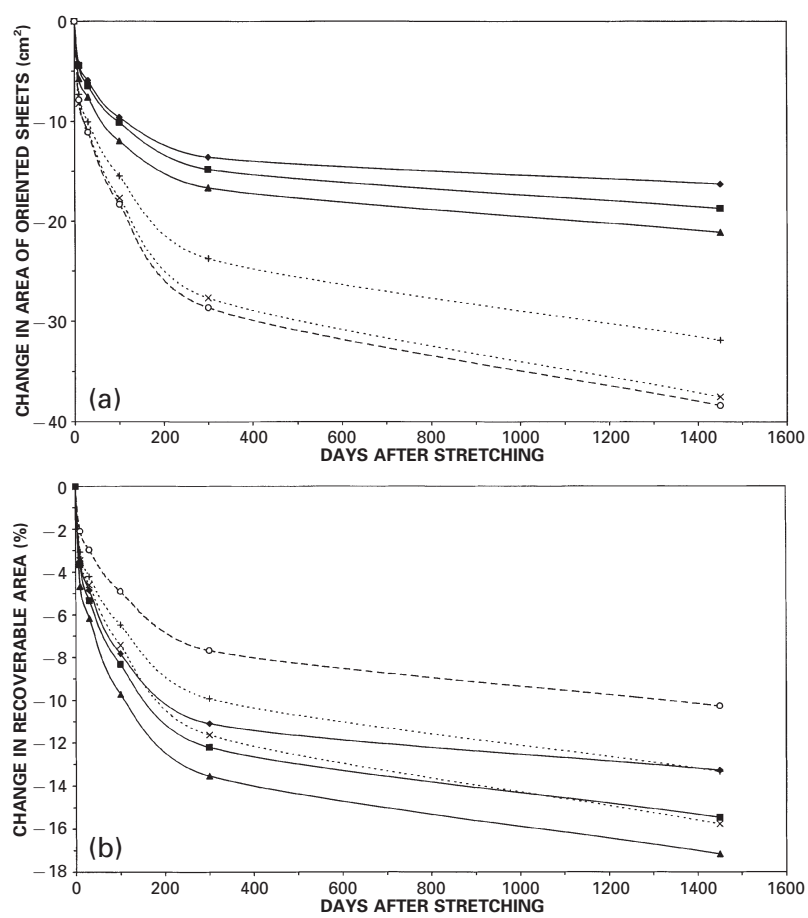

\begin{tabular}{llllr} 
Symbol & Sheet & $\begin{array}{l}\text { Draw } \\
\text { ratio }\end{array}$ & $\begin{array}{l}\text { Time, } \\
\text { min }\end{array}$ & $\begin{array}{l}\text { Temp } \\
{ }^{\circ} \mathrm{C}\end{array}$ \\
\hline$a(\bullet)$ & 3 & 1.49 & 10 & 110 \\
$a(\mathbf{\square})$ & 2 & 1.49 & 10 & 100 \\
$a(\mathbf{\Delta})$ & 1 & 1.49 & 10 & 90 \\
$a(+)$ & 5 & 1.84 & 10 & 90 \\
$a(\times)$ & 4 & 1.84 & 2 & 90 \\
$a(\bigcirc)$ & 6 & $2 \cdot 18$ & 10 & 90 \\
$b(\bigcirc)$ & 6 & $2 \cdot 18$ & 10 & 90 \\
$b(+)$ & 5 & 1.84 & 10 & 90 \\
$b(\bullet)$ & 3 & 1.49 & 10 & 110 \\
$b(\times)$ & 4 & 1.84 & 2 & 90 \\
$b(\mathbf{\square})$ & 2 & 1.49 & 10 & 100 \\
$b(\mathbf{\Delta})$ & 1 & 1.49 & 10 & 90
\end{tabular}

9 a Room temperature recovery of biaxially oriented plasticised PVC and $b$ room temperature recovery of biaxially oriented plasticised PVC as percentage of maximum recoverable area (sheets given in Table 10)

Draw ratio has little effect upon the shrinkage onset temperature of rigid PVC or upon the 5 and $50 \%$ area shrinkage temperatures for any of the three formulations. It is important to stress the correct interpretation of the latter result. Increasing the biaxial draw ratio increases the maximum recoverable area in oriented PVC sheets. When samples of oriented sheets with different draw ratios were examined by TMA, larger dimensional changes were found at higher draw ratios (Fig. $3 a$ and b). However, when these dimensional changes were related to the corresponding maximum recoverable area, shrinkage

Table 9 Tensile properties for oriented plasticised PVC 100 days and 800 days after stretching

\begin{tabular}{llllll}
\hline & \multicolumn{2}{l}{100 days } & & & \multicolumn{2}{l}{800 days } \\
\cline { 2 - 3 } \cline { 5 - 6 } Sample & $\sigma_{\mathrm{B}}, \mathrm{MPa}$ & $\varepsilon_{\mathrm{B}}, \%$ & & $\sigma_{\mathrm{B}}, \mathrm{MPa}$ & $\varepsilon_{\mathrm{B}}, \%$ \\
\hline T31 & $49 \cdot 6$ & 227 & & $45 \cdot 9$ & 242 \\
T32 & $57 \cdot 5$ & 140 & & $55 \cdot 7$ & 159 \\
T71 & $27 \cdot 4$ & 291 & & $26 \cdot 8$ & 311 \\
T72 & $29 \cdot 8$ & 233 & & $30 \cdot 8$ & 262 \\
\hline
\end{tabular}

Plastics, Rubber and Composites 2000 Vol. 29 No. 3 
behaviour as a function of temperature was found to be unaffected by draw ratio (Fig. $5 a$ and $b$ ).

While higher draw rate does improve the area shrinkage temperatures of the plasticised PVC formulations it is clear that annealing is the most significant factor in determining dimensional stability of oriented PVC. Longer annealing times and annealing at temperatures above the draw temperature both result in delayed shrinkage, with the latter having the stronger effect. Overall the results show that thermal shrinkage of oriented PVC depends upon thermal history during drawing and annealing. When oriented sheets with different draw ratios have the same thermal history, they have similar shrinkage behaviour. However, the dimensional stability of oriented PVC initially established by drawing can be improved by altering the post-draw annealing conditions. The changes in the quality of crystallites due to annealing appears to be a major factor in this process. Taylor and Tobias ${ }^{12}$ reported similar effects to those described above. Uniaxially oriented samples of PVC showed similar shrinkage onset temperatures at different draw ratios and the dimensional stability of biaxially oriented samples was improved by heat setting at temperatures above the draw temperature.

As stated in the 'Introduction' the principal aim of this work has been to search for structure-property relationships in oriented PVC. Table 11 summarises the qualitative effects of changing drawing and annealing conditions on the properties of oriented PVC. The only strong correlation is that between tensile strength and $\mathrm{A}$ peak ratio when draw ratio is the variable. To illustrate this, the appropriate data from Table 4 are plotted in Fig. 10. Table 11 also reveals that while annealing has a significant influence on A peak intensity and dimensional stability it does not have any effect on tensile strength. The implication of this result is that the tensile strength of oriented PVC cannot solely depend on the distribution and nature of the crystallites. As drawing produces chain alignment in the amorphous regions of the network, which form the majority of the structure, at the same time as generating crystallite orientation, it is suggested that tensile strength is related primarily to 'order' developed in amorphous regions. It has been shown by Gilbert et al. ${ }^{8}$ that birefringence, which measures total orientation, correlates well with tensile strength for rigid PVC samples produced under a wide range of conditions, i.e. crystallite orientation is a minor contributor to tensile strength. If annealing conditions are then assumed to

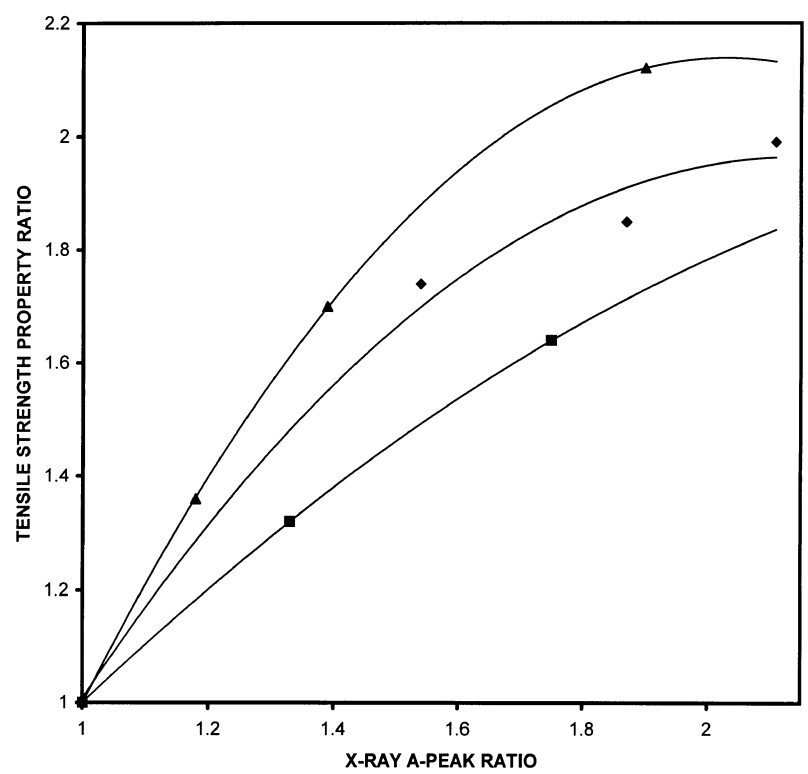

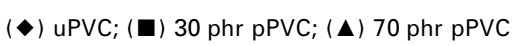

10 Relationship between tensile strength property ratio and $X$-ray $A$ peak ratio for oriented PVC

affect only the crystallites in the structure then the observed changes in A peak intensity and dimensional stability can occur without tensile strength being affected.

An important result regarding the properties of oriented PVC can be drawn from this work. To optimise the enhancement of mechanical strength in oriented PVC products the material has to be drawn towards its maximum biaxial draw ratio at $90^{\circ} \mathrm{C}$. The dimensional stability of oriented products can be improved by annealing at temperatures above $90^{\circ} \mathrm{C}$. Consequently optimum mechanical property enhancement and best dimensional stability cannot be achieved in the same oriented PVC product.

Increasing draw rate causes an unusual combination of effects in oriented plasticised PVC. The A peak ratio is reduced while dimensional stability is improved. The reason for this is not fully understood. In more crystalline polymers, stretching rate substantially increases crystallisation rate, which could increase crystallinity and hence improve dimensional stability. However, it could also cause heating, thus increasing relaxation so that crystallite alignment is reduced. This is a very tentative explanation, which requires further investigation.

Table 10 Properties of $30 \mathrm{phr}$ plasticised PVC formulation containing DIDP biaxially drawn at $50 \mathrm{~mm} \mathrm{~min}^{-1}$ and $90^{\circ} \mathrm{C}$

\begin{tabular}{|c|c|c|c|c|c|c|c|c|c|}
\hline \multirow[b]{2}{*}{ Sheet } & \multirow{2}{*}{$\begin{array}{l}\text { Anneal } \\
\text { temp., } \\
{ }^{\circ} \mathrm{C}\end{array}$} & \multirow{2}{*}{$\begin{array}{l}\text { Anneal } \\
\text { time, } \\
\text { min }\end{array}$} & \multirow{2}{*}{$\begin{array}{l}\text { Draw ratio } \\
\text { after removal } \\
\text { from BASE }\end{array}$} & \multicolumn{2}{|c|}{$\begin{array}{l}\text { Tensile strength, } \\
\mathrm{MPa}\end{array}$} & \multicolumn{2}{|c|}{$\begin{array}{l}\text { Elongation at } \\
\text { break, \% }\end{array}$} & \multicolumn{2}{|c|}{$\begin{array}{l}5 \% \text { area shrinkage } \\
\text { temp., }{ }^{\circ} \mathrm{C}\end{array}$} \\
\hline & & & & $\begin{array}{l}\text { After } \\
50 \text { days }\end{array}$ & $\begin{array}{l}\text { After } \\
500 \text { days }\end{array}$ & $\begin{array}{l}\text { After } \\
50 \text { days }\end{array}$ & $\begin{array}{l}\text { After } \\
500 \text { days }\end{array}$ & $\begin{array}{l}\text { After } \\
50 \text { days }\end{array}$ & $\begin{array}{l}\text { After } \\
500 \text { days }\end{array}$ \\
\hline 1 & 90 & 10 & $1 \cdot 49$ & $43 \cdot 7$ & $48 \cdot 7$ & 182 & 200 & 54.5 & $61 \cdot 7$ \\
\hline 2 & 100 & 10 & $1 \cdot 49$ & $43 \cdot 9$ & 48.0 & 209 & 210 & 56.6 & $63 \cdot 2$ \\
\hline 3 & 110 & 10 & $1 \cdot 49$ & 48.5 & 49.5 & 222 & 220 & $57 \cdot 1$ & $66 \cdot 7$ \\
\hline 4 & 90 & 2 & $1 \cdot 84$ & $\ldots$ & $\ldots$ & $\ldots$ & $\ldots$ & 53.4 & $58 \cdot 6$ \\
\hline 5 & 90 & 10 & $1 \cdot 84$ & $58 \cdot 4$ & $57 \cdot 9$ & 163 & 151 & $54 \cdot 0$ & 60.0 \\
\hline 6 & 90 & 10 & $2 \cdot 18$ & $67 \cdot 9$ & 69.9 & 101 & 125 & $54 \cdot 1$ & 58.9 \\
\hline
\end{tabular}




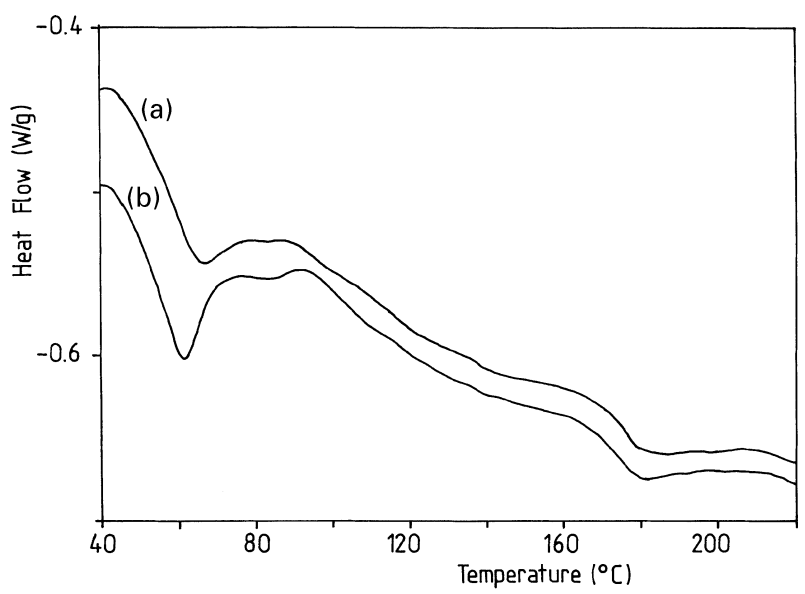

11 Thermal analysis traces for aged samples of $a$ unoriented and $b$ oriented plasticised PVC

\section{Time dependent behaviour}

As time dependent behaviour is very similar at both plasticiser levels the changes are discussed in terms of the $30 \mathrm{phr}$ plasticised PVC formulations. The particular instance of the $70 \mathrm{phr}$ plasticised PVC formulation behaving differently is also examined. The recovery of oriented plasticised PVC during room temperature storage is generally affected by drawing and annealing parameters in the same way as thermal shrinkage (as determined by TMA). Increasing both the annealing time and the annealing temperature slows room temperature recovery and also delays shrinkage on heating. However, while increasing the draw ratio also slows room temperature recovery (Fig. 9b) it does not affect thermal stability. A possible explanation for this difference is offered. The processes of thermal shrinkage and room temperature recovery are driven by different thermal effects. Shrinkage is generated by heating at a controlled rate, while recovery occurs because the oriented material is stored at a temperature above $T_{\mathrm{g}}$. In the latter case the initial amount of crystallite alignment in the oriented sheet does appear to influence dimensional change.

It is well known that room temperature storage of flexible PVC results in physical aging. ${ }^{4}$ This is accompanied by an increase in hardness and density,

Table 11 Qualitative effect of draw and anneal variables on properties of oriented PVC*

\begin{tabular}{lclll}
\hline $\begin{array}{l}\text { Increasing } \\
\text { variable }\end{array}$ & $\begin{array}{l}\text { Plasticiser } \\
\text { content }\end{array}$ & $\begin{array}{l}\text { Tensile } \\
\text { strength }\end{array}$ & $\begin{array}{l}\text { A peak } \\
\text { ratio }\end{array}$ & $\begin{array}{l}\text { Dimensional } \\
\text { stability }\end{array}$ \\
\hline Draw ratio & 0 & $\uparrow \uparrow$ & $\uparrow \uparrow$ & $=$ \\
& 30 & $\uparrow \uparrow$ & $\uparrow \uparrow$ & $=$ \\
& 70 & $\uparrow \uparrow$ & $\uparrow \uparrow$ & $=$ \\
Draw rate & 0 & $=$ & $=$ & $=$ \\
& 30 & $=$ & $\downarrow$ & $\uparrow$ \\
Anneal temp. & 0 & $?$ & $\downarrow$ & $\uparrow$ \\
& 30 & $=$ & $\uparrow$ & $\uparrow \uparrow$ \\
& 70 & $=$ & $\uparrow$ & $\uparrow \uparrow$ \\
Anneal time & 0 & $\downarrow$ & $\uparrow$ & $\uparrow \uparrow$ \\
& 30 & $=$ & $\uparrow$ & $\uparrow$ \\
& 70 & $?$ & $\uparrow$ & $\uparrow$ \\
\hline
\end{tabular}

* Key: $\uparrow \uparrow$ substantial improvement; $\uparrow$ or $\downarrow$ significant change; = no significant change; ? effect unclear.

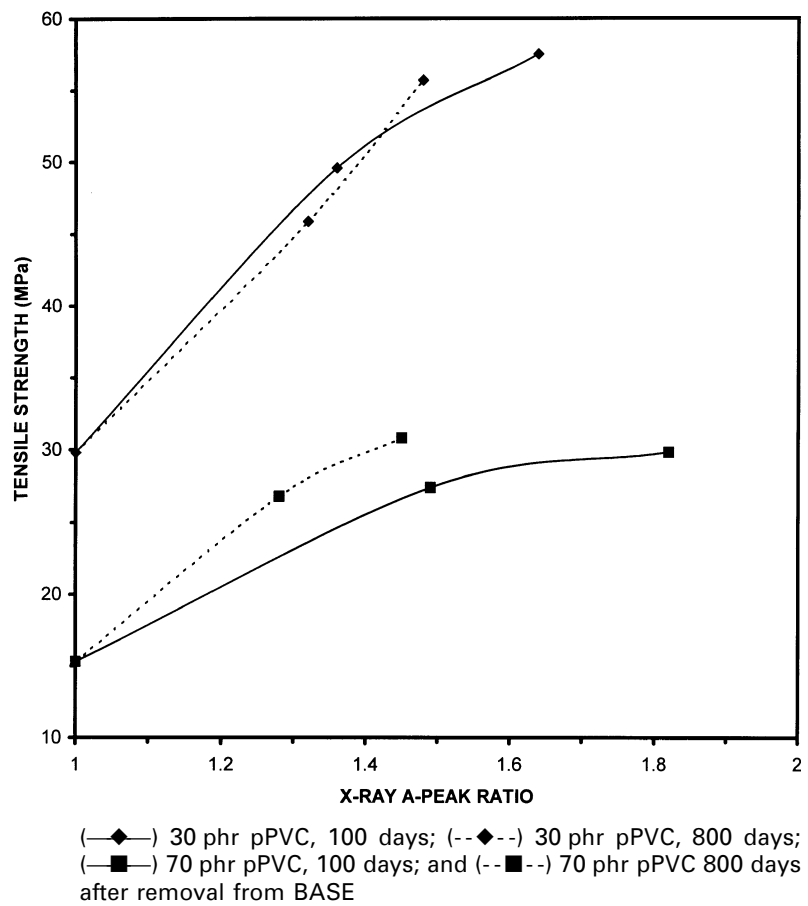

12 Change in relationship between tensile strength and X-ray A peak ratio with time for oriented plasticised PVC

and can be monitored by thermal analysis (see Fig. 6B of Ref.4). However, the physical aging of oriented PVC does not appear to have been reported previously. Figure 11 shows thermal analysis traces (obtained using a heating rate of $20 \mathrm{~K} \mathrm{~min}^{-1}$ ) of unoriented and oriented plasticised PVC that have been stored at room temperature for an extensive period of time. Both traces show a prominent melting endotherm at about $60^{\circ} \mathrm{C}$, typical of the low level of order produced during physical aging. The effect is magnified in the oriented sample, which is reasonable since the aligned chains can pack more readily. The presence of this peak retards shrinkage until melting occurs, hence the improvement in the dimensional stability of oriented sheets with time. Furthermore, the shape of the room temperature recovery curves, Fig. $9 a$ and $b$, is very similar to the physical aging curves in Ref. 4, suggesting that the aging process may be a major contributor to long term recovery at room temperature.

The decrease in X-ray A peak ratio with time follows recovery. Initially, as recovery progresses and draw ratio decreases, crystallites move out of the plane of the film and a fall in A peak intensity occurs. The eventual stabilisation of X-ray A peak ratio at a constant value suggests that after sufficient time a permanent level of crystallite orientation persists in the sheet, unless the sheet is heated and is forced to shrink. The crystallinity produced by physical aging may help to 'lock' crystallite orientation in place. The continual loss in A peak intensity with time for the $70 \mathrm{phr}$ plasticised PVC formulation is because its $T_{\mathrm{g}}$ is much lower than that of the $30 \mathrm{phr}$ plasticised formulation and so its recovery must go on for longer. It is unclear as to whether any level of permanent crystallite orientation will eventually remain in this material. 
The time dependent data have provided further evidence to support the argument that the tensile strength of oriented PVC is not solely dependent upon the distribution and nature of the crystallites. The fall in A peak intensity accompanied by little change in tensile strength confirmed this and led to a reassessment of the relationship between these properties for plasticised PVC as shown in Fig. 10. While a strong correlation exists, such a figure can only represent the relationship between tensile strength and A peak ratio for plasticised PVC at the time these properties are measured. Figure 12 shows the tensile properties of Table 9 plotted against A peak ratio for the two plasticiser levels. (The corresponding A peak ratios after 100 and 800 days were estimated from Fig. 7.) This confirms that the correlation between tensile strength and A peak ratio persists over time and that the shift in the relationship is more pronounced at the higher plasticiser level.

\section{CONCLUSIONS}

$\mathrm{X}$-ray diffraction has shown that drawing produces crystallite orientation in the plane of oriented poly (vinyl chloride) (PVC) sheets. Under the particular circumstances when draw ratio is the only variable, the increase in crystallite orientation correlates very well with enhanced tensile strength. Annealing for longer times, and especially at temperatures above the draw temperature, perfects the structure of existing crystallites leading to increased A peak intensity and improved dimensional stability, while tensile strength remains unchanged. These results lead to the conclusion that tensile strength is not solely related to crystallite orientation but is also dependent upon chain alignment in the amorphous regions of the PVC network structure. The changes in the properties of oriented plasticised PVC with time have provided strong evidence to support this conclusion.
The greatest enhancement in tensile strength of oriented PVC is achieved by stretching the material towards its maximum draw ratio at $90^{\circ} \mathrm{C}$. To optimise the thermal stability of oriented PVC annealing at a temperature above $90^{\circ} \mathrm{C}$ is necessary. The fact that PVC has its peak extensibility at $90^{\circ} \mathrm{C}$ means these two desirable properties cannot be optimised in the same oriented PVC sheet.

\section{REFERENCES}

1. M. GILBERT, D. J. HITT, and M. J. B. HARTE: Plast. Rubber Compos. Process. Appl., 1994, 22, (3), 177-183.

2. D. J. HITT and M. GILBERT: Mater. Sci. Technol., 1992, 8, 739-745.

3. D. J. HitT and M. GILbert: Polym. Test., 1994, 13, 219237.

4. M. GILbert: JMS C Rev. Macromol. Chem. Phys., 1994, 34, (1), 77-135.

5. G. natta and P. Corradini: J. Polym. Sci., 1956, 20, 251-266.

6. Z. LIU and M. GILBERT: Polymer, 1987, 28, 1303-1308.

7. C. BAKer, W. F. MAdDams, and J. E. PREedy: J. Polym. Sci., 1977, 15, 1041-1054.

8. M. Gilbert, Z. LiU, and D. J. HitT: Polym. Eng. Sci., 1997, 37, (11), 1858-1864.

9. A. J. De VRIES and C. BOnNeBAT: Polym. Eng. Sci., 1976, 16, (2), 93-100.

10. T. PAKUla and M. TRZNADEL: Polymer, 1985, 26, 10111018.

11. M. TRZNADEL and M. KRYSZEWSKI: Polymer, 1988, 29, 418-425.

12. J. W. tObias and L. J. TaYlor: J. Appl. Polym. Sci., 1975, 19, $1317-1322$.

13. T. Kato and N. Yanagihara: J. Appl. Polym. Sci., 1981, 26, 2139-2145.

14. B. HAWORTH, Z. W. DONG, and P. DAVIDSON: Polym. Int., 1993, 32, 325-335.

15. J. C. VyVodA, M. GILbert, and D. A. Helmsley Polymer, 1980, 21, 109-115. 